\title{
La Etnoeducación como Posicionamiento Político e Identitario del Pueblo Afroecuatoriano por Rocio Vera
} Santos

\author{
MONIZ, Elias Alfama' \\ BAUTISTA, Victoria Maldonado²
}

\section{RESUMEN}

La presente reseña es un resumen crítico sobre el artículo académico La etnoeducación como posicionamiento político e identitario del pueblo afroecuatoriano, de Rocío Vera Santos. Un texto científico que dilucida a través de una investigación de corte cualitativo y una puesta teórica postcolonial y decolonial el proceso de consolidación y ejecución del proyecto de etnoeducación afroecuatoriana. Se trata de un proyecto político, epistemológico y educativo que se viene gestando en las últimas tres décadas, y con el cual el movimiento social afroecuatoriano se posesionan frente al Estado; intentando subvertir el legado de la colonización, mediante estrategias, practicas pedagógicas e iniciativas autónomas que revitalizan y rescatan los saberes ancestrales, la memoria y la tradición oral. El objetivo de esta propuesta de educación étnica busca el fortalecimiento de la identidad, la reparación histórica y sostener la lucha antirracista.

Etnoeducación afroecuatoriana. Identidad. Políticas de representación. Saberes ancestrales. Movimiento social afroecuatoriano.

\section{A etnoeducação como posicionamento político e identitário do povo afro-equatoriano Rocio Vera Santos}

\section{RESUMO}

Esta revisão é um resumo crítico do artigo acadêmico a etnoeducação como posição política e identitária do povo afro-equatoriano, de Rocío Vera Santos. Um texto científico que elucida por meio de uma investigação qualitativa e de uma configuração teórica pós-colonial e descolonial o processo de consolidação e execução do projeto de etnoeducação afro-equatoriana. É um projeto político, epistemológico e educacional que vem se desenvolvendo nas últimas três

\footnotetext{
${ }^{1}$ Doctor en História Social por la Pontifícia Universidad Católica de São Paulo Professor Visitante, Programa Multidisciplinar de Pós-Graduação em Estudos Étnicos e Africanos - PÓSAFRO/UFBA. E-mail: eliasalfamamoniz@yahoo.com.br. Lattes: http://lattes.cnpq.br/7907484410705725. Orcid: https://orcid.org/0000-0003-4748-3866.

2 Mestranda por el Programa Multidisciplinar de Pós-Graduação em Estudos Étnicos e Africanos - PÓSAFRO/UFBA. Email: victoriamaldonadobautista@gmail.com Lattes: http://lattes.cnpq.br/3446679574591406. Orcid: https://orcid.org/0000-0001-7262-4662.
} 
décadas, e com o qual o movimento social afro-equatoriano se posesiona diante do Estado; tentando subverter o legado da colonização, por meio de estratégias, práticas pedagógicas e iniciativas autônomas que revitalizam e resgatam saberes ancestrais, memória e tradição oral. O objetivo desta proposta de educação étnica busca fortalecer a identidade, reconstruir a história e sustentar a luta anti-racista.

Etnoeducação afro-equatoriana. Identidade. Políticas de representação. Saberes ancestrais. Movimento social afro-equatoriano.

\section{Ethnoeducation as a political and identity position of the Afro-Ecuadorian people}

\section{ABSTRACT}

This review is a critical summary of the academic article Ethno-education as a political and identity position of the Afro-Ecuadorian people, by Rocío Vera Santos. A scientific text that elucidates through a qualitative investigation and a postcolonial and decolonial theoretical setting the process of consolidation and execution of the Afro-Ecuadorian ethno-education project. It is a political, epistemological and educational project that has been developing in the last three decades, and with which the Afro-Ecuadorian social movement takes possession in front of the State; trying to subvert the legacy of colonization, through strategies, pedagogical practices and autonomous initiatives that revitalize and rescue ancestral knowledge, memory and oral tradition. The objective of this ethnic education proposal seeks to strengthen identity, historical reparation and sustain the anti-racist struggle.

Afro-Ecuadorian ethno-education. Identity. politics of representation. Ancestral knowledge. Afro-Ecuadorian social movement.

\section{Etnoeducazione come posizionamento politico e identitario del popolo afro-ecuadoriano}

\section{SOMMARIO}

Questa recensione è una sintesi critica dell'articolo accademico Etnoeducazione come posizione politica e identitaria del popolo afro-ecuadoriano, di Rocío Vera Santos. Un testo scientifico che delucida attraverso un'indagine qualitativa e una impostazione teorica postcoloniale e decoloniale il processo di consolidamento ed esecuzione del progetto etno-educativo afro-ecuadoriano. È un progetto politico, epistemologico ed educativo che si è andato sviluppando negli ultimi tre decenni, e di cui il movimento sociale afro-ecuadoriano si impadronisce di fronte allo Stato; cercando di sovvertire l'eredità della colonizzazione, attraverso strategie, pratiche pedagogiche e iniziative autonome che rivitalizzano e salvano la conoscenza ancestrale, la memoria e la tradizione orale. L'obiettivo di questa 
proposta di educazione etnica cerca di rafforzare l'identità, la riparazione storica e sostenere la lotta antirazzista.

\section{Etnoeducazione afro-ecuadoriana, identità, politica di rappresentanza, saperi ancestrali, movimento sociale afro-ecuadoriano.}

Rocío Vera Santos es Doctora en Sociología. Docente e investigadora científica en el Instituto de Estudios Latinoamericanos, de la Universidad Libre de Berlín, en Alemania. El artículo a ser analizado fue parte de un encuadre teórico de su tesis doctoral Dinámicas de la negritud y africanidad. Construcciones de la Afrodescendencia en Ecuador presentada en el 2015. Posteriormente su tesis fue publicada por la editorial Abya Yala, y reconocida como la mejor obra en Ciencias Sociales a Nivel Nacional en el 2016, además de recibir el premio Isabel Tobar Guaderas por parte del Municipio de Quito, Ecuador. (LEON, 2018).

El articulo La etnoeducación como posicionamiento político e identitario del pueblo afroecuatoriano, fue publicado en la Revista Antropologías del Sur N8 en el 2017. El interés por traer a la reflexión el artículo de Rocío Vera Santos, se debe al minucioso trabajo de análisis teórico y de interpretación que la autora hace sobre el proceso de etnoeducación afroecuatoriana. Cabe recalcar también que es uno de los pocos materiales académicos que existen sobre el tema, por lo que la labor de la autora al dejar un registro sobre los procesos políticos de los afroecuatorianos se convierte un aporte fundamental para el reconocimiento de las luchas sociales que vienen forjando históricamente los sujetos líderes y lideresas de las comunidades afrodescendientes del Ecuador.

Inicialmente la autora aborda en la introducción de su investigación a manera de reseña histórica el proceso de los afrodescendientes en el Ecuador, desde la llegada de sus ancestros africanos a dicho territorio. Expone dentro de este marco histórico tanto las estrategias de resistencias y organización de los afroecuatorianos que las denomina como en "pro de la libertad y la democracia" (VERA, 2017) desde el periodo colonial hasta la actualidad, así como también las problemáticas que devienen de un régimen racializado fundado en el colonialismo y la esclavitud. Régimen que sostiene la desigualdad y el racismo como elementos que refuerzan el silenciamiento e invisibilización de la historia los aportes culturales, sociales de dicho grupo social a la construcción de la nación.

Más adelante dentro de esta historización, Vera menciona que entre los años 1980 y 1990, ocurre el reconocimiento de las identidades étnicas por parte del Estado Ecuatoriano debido a la influencia del contexto internacional que estaba pasando por la creación e incorporación de políticas multiculturales en América latina. Dentro del contexto nacional los procesos de organización y movilización social se convirtieron en un escenario en el que los pueblos 
originarios y afroecuatoriano demandaban una reparación histórica, reconocimiento y la creación de políticas públicas que beneficien a sus pueblos y nacionalidades. Es dentro de este contexto de movilización social que el proyecto de etnoeducación afroecuatoriana empieza a concebirse.

En un segundo momento, el artículo consta de reflexiones teóricas bajo una perspectiva postcolonial y de colonial, que traen al análisis los aportes de Stuart Hall (1996) y su obra "Questions of Cultural Identity" sobre articulaciones identitarias, nuevas etnicidades, y políticas y estrategias de representación. Otra referencia teórica se basa en el pensamiento de Aníbal Quijano (1992) sobre la Colonialidad del poder, así como también el concepto de Atlántico negro (1993) de Paul Gilroy. Los conceptos orientadores que presenta de Stuart Hall son las políticas de representación y el lugar de enunciación, en el que la autora reconoce dentro de esas categorías analíticas como los sujetos racializados fueron construidos a través de discurso que los mantienen en posiciones fijas que lo estereotipan, discriminan y crean relaciones de poder desiguales. Según Vera siguiendo el análisis de Hall, es a través de un proceso de subjetivación que aquel sujeto consigue tener una agencia y representación propia que le permite constituir una nueva forma de etnicidad. Es decir, se positiva esa subjetividad para crear nuevas formas de representación que rompen con lo determinado y le permiten al sujeto posicionarse con una narrativa propia que hable de su historia, tradición, memoria y lugar histórico. (VERA, 2017).

Sobre Aníbal Quijano pronuncia como la colonialidad del poder constituyo el pensamiento eurocéntrico como la única fuente fidedigna de conocimiento, expresa como opero el poder colonial basado en discursos de prejuicio, clasificación y subalternización hacia los grupos humanos considerados como inferiores. Discursos y prácticas simbólicas manejadas por las elites hegemónicas que tienen el dominio del desarrollo económico global. En otras palabras, la tradición intelectual occidental subordina a ciertos grupos humanos, y esta forma de dominación se encuentra todo el tiempo actualizándose mediante practicas de exclusión y racialización, basada en la reproducción de diferencias.

Vera dialoga con el concepto de Atlántico Negro para hacer referencia a los procesos de movilización social por parte diáspora africana en América, se refiere también a la creación de una cultura negra transnacional que adapta su legado como para combatir el racismo estructural, en palabras de la autora:

En este sentido se entiende el Atlántico Negro como un espacio de articulación de antirracismo, en donde se postula que lo que vincula a las diversas poblaciones afrodescendientes no es necesariamente la ancestralidad africana, ni los rasgos físicos, sino las experiencias similares de opresión racista y de lucha contra la discriminación. (VERA, 2017, p. 85). 
Estas categorías de análisis son utilizadas a lo largo del texto, para interpretar las acciones y trayectoria del proyecto de etnoeducación afroecuatoriana como una política de representación, identificar en el material empírico de su trabajo de campo, que consistió en hacer entrevistas a los líderes afroecuatorianos que participaron en este proceso, los lugares de enunciación, y en el análisis del contenido y material pedagógico generado para impartir las clases de etnoeducación reconoce la ruptura de la colonialidad de poder ya que se crean herramientas y dispositivos pedagógicos propios apostando a las reformas curriculares para constituir un proyecto político de educación que reconozca la interculturalidad y a la vez integre los aspectos culturales e históricos silenciados de los afroecuatorianos.

\section{¿Qué es la etnoeducación afroecuatoriana o educación con identidad en Ecuador?}

El Artículo 1 del Acuerdo Ministerial, define a la Etnoeducación Afroecuatoriana como un proceso educativo, cultural, social, político y epistémico permanente, orientado al fortalecimiento de la cultura del pueblo afroecuatoriano, a partir de la interiorización y la reproducción de los valores y saberes propios. Permite mantener su identidad y sus particularidades culturales en el marco de un proyecto de vida colectivo, contribuyendo de esta manera a la interculturalidad del país. (Acuerdo Ministerial 00045-A, 20 de mayo del 2016).

Dentro de esta definición la autora divide su análisis en dos categorías propuestas por el pensador afroecuatoriano y gestor de la propuesta etnoeducativa Juan García, estas categorías se denominan "Casa adentro" y "Casa Afuera" y tienen como finalidad explicar cómo se desarrolla la etnoeducación dentro de los contextos locales y fuera de estos. Por un lado, "Casa adentro" hace referencia a:

Las estrategias de representación de la sociedad civil afroecuatoriana y de actores religiosos y académicos que desde 1979 de manera localizada han elaborado y difundido material etnoeducativo a fin de contrarrestar la invisibilización de los aportes del pueblo afroecuatoriano en la construcción del Estado Nación y modificar con ello la visión racista, estereotipada y homogénea que la sociedad blanco mestiza ha construido sobre ellos. (2017, p.81).

Sobre el proceso "Casa Adentro" a continuación una contextualización. En 1979, por un lado se crea el Centro de Estudios Afroecuatorianos (CEA), liderado por Juan García - intelectual, pensador, escritor y profesor afroecuatoriano que forjó la identidad militante afroecuatoriana desde la revitalización de la tradición oral y la conexión con la ancestralidad. García hace 
un trabajo de registro de la memoria y tradición oral en las comunidades afrodescendientes del Ecuador durante la década de los 80 junto a otros estudiantes universitarios afroecuatorianos, intelectuales y líderes que eran parte de CEA, que habían migrado desde las provincias rurales hacia la Capital del Ecuador, Quito.

Por el otro, en 1981 surge el Centro Cultural Afroecuatoriano (CCA). Este fue un espacio creado por los misioneros Combonianos y la Pastoral Afroamericana, quienes hicieron un trabajo de captación y formación de liderazgos afroecuatorianos, constituyendo la primera organización política social de afroecuatorianos llamada MAEC (Movimiento Afroecuatoriano Conciencia). Fundaron las primeras bibliotecas y centros de estudio con temáticas afrodiaspóricas. En este espacio también se impartían clases de teología afroamericana, ciencias sociales, se estudiaba historia americana y africana y sobre la diáspora africana en América. Aquí también sucedían encuentros de familias negras, mediante convocatorias para formar grupos que recreen manifestaciones ancestrales y culturales, como la danza, gastronomía y música afroecuatoriana. Los misioneros Combonianos dedican parte de su tiempo a la investigación de archivo, aportando al primer intento formal para construir historiografía afroecuatoriana.

Un segundo periodo, de proceso "Casa adentro" se da en 1999, este se desarrolla en el marco de un encuentro que convocó Juan García cuando acude nuevamente a las comunidades afroecuatorianas en el interior del país, ubicadas en las provincias de Esmeraldas e Imbabura. Con el objetivo de impartir talleres sobre etnoeducación, además de devolver formalmente las memorias de sus registros y documentaciones que recopiló desde 1979. García "invita a los líderes y profesores afroecuatorianos a ser parte del proyecto de etnoeducación para descolonizar la educación y hablar e impartir conocimientos desde la cosmovisión afroecuatoriana." (MALDONADO, 2015, p.48). Las reflexiones y conclusiones de los participantes de este taller definían a la iniciativa de Juan García como:

un espacio para hablar con nuestra propia voz, ya que recuperar el uso de la palabra, para decir lo que hace cientos de años queremos decir, es un ejercicio saludable, así como el poder mostrar a los otros ecuatorianos lo que realmente somos, ayudará mucho en la búsqueda del respeto mutuo entre pueblos y culturas diferentes. (GARCÍA, 1999. sp).

En este taller de sensibilización se conforma la "Comisión o Mesa de Etnoeducación". Más adelante en el 2005 se publica el Módulo "Nuestra Historia" como un material pedagógico resultado de las reuniones de sensibilización que hizo Juan García, este insumo se empieza aplicar de manera autónoma (y no oficial en la malla curricular) como clases de Etnoeducación en dos colegios del Valle del Chota (comunidades afroecuatorianas andinas ubicadas al norte de 
Ecuador), bajo la iniciativa y responsabilidad de los profesores afroecuatorianos que trabajaban en aquellos establecimientos. (MALDONADO, 2015).

En el 2008, se lleva a cabo un taller de Concertación Temática, aquí se designó un equipo para la elaboración de las nuevas guías etnoeducativas llamadas "Orígenes" en miras de ampliar a otros espacios educativos del Ecuador esta propuesta de enseñanza y hacer ajustes para mejorar la temática y los contenidos de los módulos anteriores, aquí se conjugaron tanto, los aportes de las investigaciones de tradición oral de Juan García, y el material de investigación historiográfica elaborado por los misioneros Combonianos, es decir las contribuciones producidas por el CCA y el CEA.

Finalmente, en el año 2016, después de un proceso de tres décadas, el proyecto de Etnoeducación Afroecuatoriana fue oficializado dentro del Estado mediante Acuerdo Ministerial 00045-A, expedido por el Ministerio de Educación del Ecuador el 20 de mayo del 2016. Convirtiéndose en una política pública sobre educación étnica afrodescendiente que integra este proceso pedagógico al sistema educativo formal, lo que la autora definiría dentro de las categorías conceptuales que propuso Juan García como "Casa afuera", que "se constituye por los espacios para compartir con los otros, (Estado y Sociedad), usando los canales de la interculturalidad que propone la nación, a fin de enseñar a los otros sobre la realidad afroecuatoriana (PABÓN, 2011 apud VERA, 2017, p. 83).

Rocío Vera Santos concluye el articulo con un serie de reflexiones en las que argumenta que la etnoeducación "se ha constituido en una herramienta esencial para fortalecer la identidad afroecuatoriana y para confrontar el racismo estructural y la discriminación institucionalizada" (2017, p.82). La iniciativa del proyecto de etnoeducación busca hacer una reorientación epistemológica, para romper con la hegemonía del pensamiento civilizatorio colonial, e irrumpir en el sistema educativo fundado en una esencia disciplinar y de silenciamientos.

\section{REFERÊNCIAS}

ACUERDO MINISTERIAL 00045-A, 20 de mayo del 2016. Disponível em https://educacion.gob.ec/wp-content/uploads/downloads/2016/05/MINEDUC-ME-201600045-A.pdf

GARCÍA, Juan.1er módulo de sensibilización. Compilador, 1999.

LEON, Edizon. Reseña del libro: Dinámicas de la negritud y africanidad. Construcciones de la Afrodescendencia en Ecuador. Mundos Plurales - Revista Latinoamericana de Políticas y Acción Pública, N 2: 129-131; 2018.

MALDONADO, Victoria. Tesis de licenciatura. Historia de vida de Barbarita Lara Calderón lideresa Afro ecuatoriana: Reflexiones en torno a su vida, procesos de liderazgo y luchas. Universidad San Francisco de Quito, 2015. 
VERA, Rocío. La etnoeducación como posicionamiento político e identitario del pueblo afroecuatoriano. Revista Antropologías del Sur. N8: 81 - 103; 2017. 